\title{
Review on the microbiologically influenced corrosion and the function of biofilms
}

\author{
J. Telegdi, ${ }^{1,2 *}$ A. Shaban ${ }^{1}$ and L. Trif ${ }^{1}$ \\ ${ }^{1}$ Institute of Materials and Environmental Chemistry, Research Centre for Natural \\ Sciences, Budapest, Hungary \\ ${ }^{2}$ Óbuda University, Faculty of Light Industry and Environmental Engineering, Budapest, \\ Hungary \\ *E-mail: telegdi.judit@ttk.hu
}

\begin{abstract}
The microbiologically/microbially influenced corrosion (MIC) is a special type of corrosion; in this case the microorganisms by their presence and aggressive metabolites alter the processes on solid surfaces via electrochemical and chemical reactions. When microorganisms are present in most cases the degradation of metals or alloys happens by microbes embedded in biofilms and by their excreted metabolites (e.g. acids), macromolecules (with complexing ability) and by other molecules that can form insoluble precipitates; all these reactions increase the deterioration. The paper summarizes the most important characteristics of the MIC, mainly the so-called biocorrosion of metals and alloys. Not only the chemical and electrochemical processes, but the roles of the corrosion relevant microorganisms in the deteriorating processes, as well as the information about the mechanisms of the MIC worked out in the past and in the very last period are discussed. The most important (aerobic, anaerobic, slime former, acid producer etc.) microorganisms, their nutrient requirements and the formation and role of biofilms are presented, characterized and discussed, as well as the influence of biofilms on the MIC is also demonstrated. The impact of metals on the MIC is also discussed. The history of the research on MIC from its discovery till the $21^{\text {th }}$ century will demonstrate the enormous work that allowed the understanding of this special type of corrosion as well as its mechanism and the role of the biofilm in MIC. The paper will expose the reactions that go on between the slimy layer (that surrounds the microorganisms even in planktonic form) and the metal surface. The mostly used techniques to visualize what on the surface happens and to measure the change in the current density/corrosion potential and in the corrosion rate due to microbial action are also summarized and in all cases the advantages and disadvantages of all methods are discussed.
\end{abstract}

Keywords: MIC, history of MIC, biofilms, biofouling, biocorrosion, corrosion relevant microorganisms, instrumentations, techniques for evaluation of MIC.

Received: August 26, 2019. Published: December 30, 2019

doi: $\underline{10.17675 / 2305-6894-2020-9-1-1}$ 


\section{History of MIC}

The microbiologically influenced corrosion is not a new type of corrosion, but its specialty is that the microorganisms with their presence (directly or indirectly) and with their aggressive metabolites enhances the rate of metal corrosion.

MIC can deteriorate metals exposed to sea water, fresh water, demineralized water, process chemicals, food stuffs, soils, aircraft fuels, human plasma, and sewage.

Microorganisms can accelerate the rates of partial reactions and cause enhanced corrosion. The microbiologically initiated/influenced corrosion was first mentioned by Garrett [1] who gave account on bacterial deterioration of lead-covered cables. The subsequent report was published by Gaines who coupled the undesired microbial deterioration with the presence of sulfur in the corrosion products [2].

After the pioneer work of von Wolzoen Kuhr and van der Flugt in 1934 [3], until the 1960s, only few publications reported practical cases. As early as in 1926 microbiologists isolated sulfate reducing bacteria in oil environment $[4,5]$.

The existence of the biofilm was first mentioned by Zobel in 1943 [6], and then intensive research on the MIC started, which led to the acceptance of this special type of corrosion initiated and enhanced (and in some cases inhibited) by microorganisms. The development was supported by the elaboration/discovery of surface analytical, electrochemical and microscopic techniques that promoted the clarification of the role of biotic and abiotic sulfide in the microbiologically influenced corrosion.

During the 1960s and the early 1970s the research on MIC was devoted to objection or verification of the anaerobic iron corrosion provoked by sulfate reducing bacteria. The researchers focused on the explanation of MIC mechanisms by the cathodic polarization theory. The hindrance of the appropriate knowledge transfer among the different specialists explains the difficulty in reaching an adequate understanding of MIC. In the 1980s, which brought a significant progress in understanding of MIC, several research groups carried out intensive work to elucidate the MIC mechanisms. An increasing intellectual and technical cross-fertilization of ideas elaborated by microbiologists, materials scientists, electrochemists improved the understanding of MIC. The 1990s brought a breakthrough in knowledge of MIC. The tardiness was not only due to the lack of cooperation among specialists (chemists, microbiologists, and metallurgists) but to the lack of special instrumentation that could measure the destructive activity of microbes involved in a biofilm.

The twenty-first century resulted in further development of new analytical methods applicable either in laboratory or at industry. One of the most exciting advances in instrumentation appeared in these years are the chemical/biochemical microsensors that can in situ analyze the changes in the oxygen level, in the $\mathrm{pH}$ value and in the concentration of different metabolites within the biofilm. Although the MIC is of electrochemical nature, the participation of microbes in these undesired reactions alters the metal-solution interface by the formation of biofilms. 
Considering the recent advances in MIC research the molecular techniques of the bacterial DNA and RNA are the most promising methods as they offer the identification of dominant bacteria in a biofilm without application of other traditional techniques; they can calculate the ratio of different microorganisms that contribute to the MIC.

To show the importance of this type of corrosion, and to try to elucidate a lot of unsolved/unanswered questions, important publications appeared on MIC in the last years. There are very good summaries (books, book chapters and publications) on the MIC that try to summarize and explain the essential phenomena of MIC [7, 8].

\section{Biofilm, influence of biofilms}

Biofilm is the general appellation of biodeposition, which can be formed when a solid surface is in contact with water. According to Charaklis the biofilm is an undesired deposition that decreases the power capacity and lifetime of instruments [9-12], mars the water quality and has substantial financial consequences. In most cases the composition of the biodeposits is inhomogeneous that contributes to an increased microbial deterioration.

From the point of view of MIC the biofilm formation is the key factor that significantly influences a solid surface deterioration. The biological changes go parallel with the microbial accumulation, biofilm formation. The corrosion relevant microbes that initiate biofilm formation and, at the same time, excrete aggressive metabolites (e.g. sulfide ions and acids) as well as exopolymeric substances (EPS) that are the most important component of a gelatinous biofilm, are dangerous. The EPS acts as glue, it ensures a "safe life" for microbes within the biofilm, where they can securely grow, propagate, excrete metabolites and are able to communicate with the same and with other microorganisms through quorum sensing molecules.

In aquatic environments the microorganisms after attaching to metals, colonize and form biofilms; the environment at the biofilm/metal interface differs radically from the bulk considering the $\mathrm{pH}$ value, the concentration of the dissolved oxygen, and organic/inorganic species. This leads to electrochemical reactions that control the corrosion rates.

The biofilm influences the metal surface as follows:

- It alters the transport of chemicals from or toward the metal surface. The biofilm forms a diffusion barrier for certain chemical species (nutrients, metabolites etc.).

- Via the biofilm the protective (passivating) film can be removed from the metal surface.

- The patchy distribution of microbiological settlement generates aeration effects, which results in formation of differential aeration cells, where areas under respiring colonies are depleted in oxygen.

- At the metal-solution interface the oxidation-reduction conditions change.

- The biofilm alters the structure of an inorganic passive layer, releases/removes the metal ions from the surface by the metabolic by-products and by the exopolymeric 
substances that can coordinate the metal ions. Formation of concentration cells is initiated.

Biofilms of different origin are divergent [13]. In most cases not only one type of microorganisms forms a biofilm but the whole community of the microbes creates a biofilm of mixed population [14-17].

\subsection{The composition of biofilms}

The main ingredient of a biofilm is water (75-90\%); the other constituents are the follows:

1. Microorganisms: bacteria (autotroph, heterotroph), fungi, algae, cianobacter, protozoa;

2. Exopolymeric substances (EPS): polysaccharides, lipopolysaccharides, humic acids, proteins, nucleic acids, lipids [18, 19]

3. Organic and inorganic materials

The biomatrixes of different origin differ significantly in most cases [20-23], their compositions depend on the nutrients [24]. The EPS guarantees the 3D arrangement of the microbes and keep them far from each other. In some cases not the EPS but proteins are the most important builder of the biofilm [25].

The structure of the EPS is assured by different weak forces:

1. van der Waals forces (hydrophobic interactions, binding energy: $2.5 \mathrm{~kJ} \cdot \mathrm{mol}^{-1}$, binding length: $0.3-0.4 \mathrm{~nm}$ ),

2. electrostatic interactions (binding force: $12-29 \mathrm{~kJ} \cdot \mathrm{mol}^{-1}$ ),

3. hydrogen bonds (binding force: $10-30 \mathrm{~kJ} \cdot \mathrm{mol}^{-1}$ ).

These forces prevail not only among in the EPS molecules but amidst the microorganisms and the organic/inorganic substances [26].

\subsection{Why do microbes like to live in biofilms?}

The corrosion relevant microorganisms are mostly dangerous in sessile form, embedded into biofilms, but much less in planktonic form. Microbes involved in biofilms and embedded in deposits are dangerous as the formation of a biofilm provides a niche for corrosive microbes to grow and proliferate.

In aqueous environments microbes readily attach to solid surfaces as the living conditions in biofilm are better and safer for them than in the planktonic existing (Figures 1 and 2).

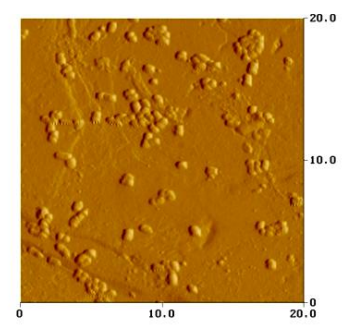

Figure 1. Microbes scattered on a solid surface (NanoScope III, Digital Instrument). 

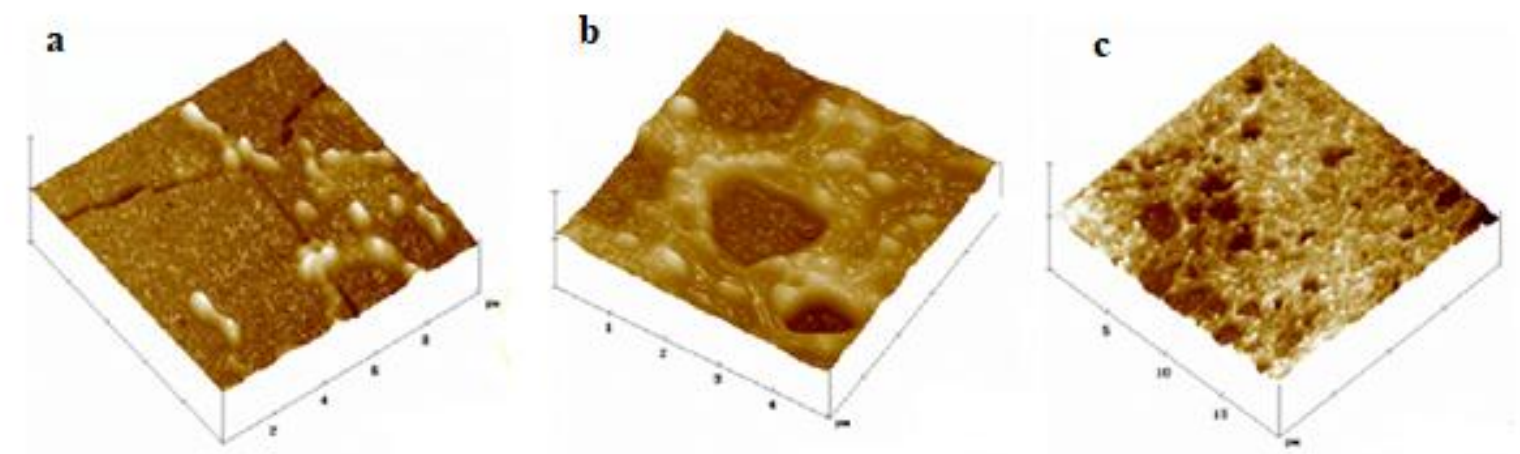

Figure 2. Biofilm formation: a: microbes adhered to the surface; $b$ : microbes embedded into EPS; c: the solid surface almost completely invaded by the biofilm (NanoScope III, Digital Instrument; $\mathrm{z}=1000 \mathrm{~nm}$ ).

Both in planktonic and in biofilm-embedded form the microbial cell walls are surrounded by exopolymeric substances (Figure 3), which are sticky and allow the adhesion of microorganisms to solids. The accumulation of microorganisms on metals, which results in biofilm (Figure 2), alters the microenvironment (the wettability, the electrostatic charge) and helps in colonization of microbes.

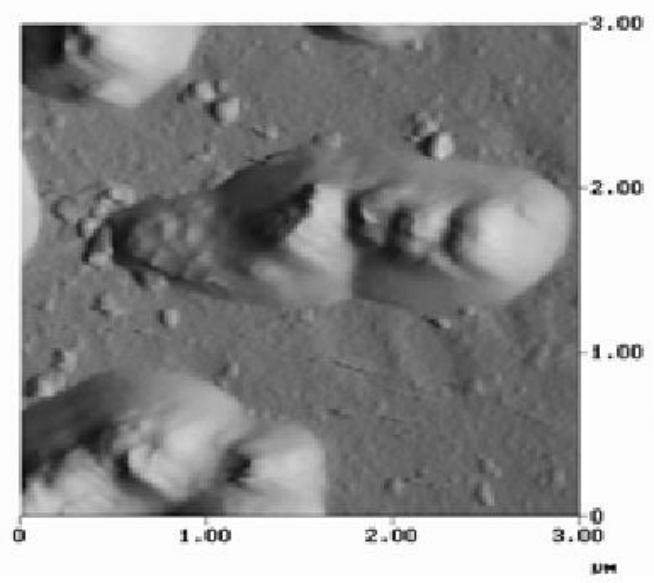

Figure 3. Leptospirillum ferrooxidans surrounded by EPS (NanoScope III, Digital Instrument).

The biofilm is not necessarily uniform in time and place (Figure 2) as well as in pH, in dissolved chemicals and in the oxygen concentration [27]. It is necessary to mention that beneath the biofilm starts the metal degradation (Figure 4). 


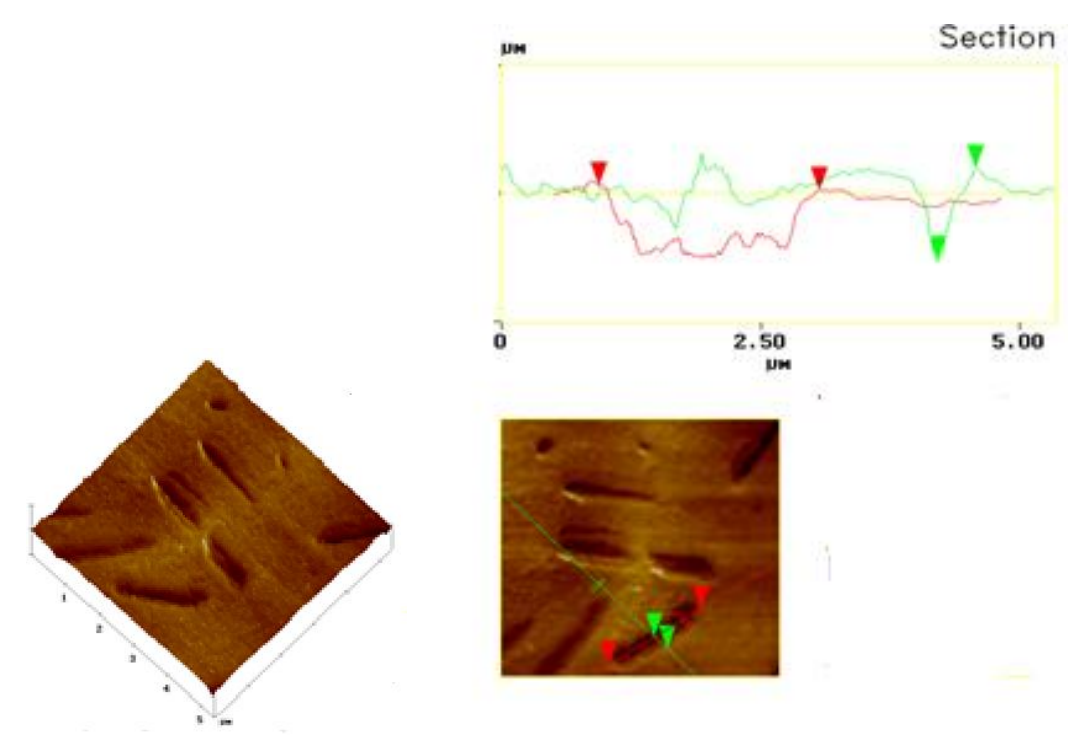

Figure 4. Iron surface etched by the acid producer Acidothiobacillus intermedia (NanoScope III, Digital Instrument; $\mathrm{z}=500 \mathrm{~nm}$ ).

\subsection{Progression in the biofilm formation}

When a biodeposition starts, the microorganisms make a transition from a free-floating planktonic to a stationary sessile lifestyle, and the result is a biofilm.

When a chemically inert substrate is immersed in aqueous environment almost immediate starts the accumulation of organic molecules on the wetted surface; first a conditional layer is formed, its composition depends on the ions, glycoproteins, humic and fulvic acids i.e. on organic compounds and inorganic ions accumulated from the aqueous environment. The adhesion of microorganisms starts reversibly and later irreversibly; it is enhanced by the presence of the EPS layer (Figure 3).

The forces responsible for the adhesion of microorganisms are electrostatic interaction and van der Waals forces - the same ones, which keep together the biofilm structure. Initial attachment of cells is controlled by physical adhesion between the microorganism and the substrate. It is also known as adsorption, when the initial colonists attach to a surface through weak, reversible bonds (which are slightly stronger than electrostatic repulsive forces) as well as by hydrogen bonds. Irreversible attachment is accomplished with secretion of further EPS that forms a sponge-like matrix. This adhesive material permanently binds the microorganisms to each other and collectively to the surface [28-30].

The biofilm continues to grow and becomes diverse by attracting more microorganisms through chemical messengers. More and more microbes accumulate and form a layer in a shorter (several minutes) or longer (some hours) time. The enhanced EPS production as well as the microbial proliferation results in a thick, gelatinous biofilm; it mainly consists of water, microorganisms of different species and other components from the aqueous environment. 
The biofilm is a dynamic system with transport processes and chemical reactions; within the biofilm there is a gradient of the $\mathrm{pH}$, ions and microbes. The number of anaerobic cells increases near to the solid surface, and the aerobes will accumulate near to the upper part of the biofilm, closer to the liquid/air interface. Their activity provides a natural environment for the anaerobes.

During the biofilm formation numerous changes happen: First, an electric double layer (that mediates the adsorption of organic molecules, mainly proteins) is established at the surface of the solid in less than a second. In the next step subunits of fibrinonectin adsorb to the surface that mediate the binding of microbial cells to the solid surface first reversibly then irreversibly via the cell membranes. When bacterial cells are bound to the surface, they undergo on a phenotypic change and the excretion of the exopolymeric substance continues. In all these periods the cells grow, proliferate, metabolize (producing more and more EPS) and form a cohesive structure known as gel-like biofilm [31]. There is a gradient in the film: near to the solid surface are the anaerobic microbes while the aerobic microorganisms are mainly located nearby the solution/air interface. Biofilm microorganisms live in customized microniche in a complex microbial community that exhibits homostasis, a primitive circulatory system and metabolic cooperativity, and each of these sessile cells reacts with its special environment in a way that differs fundamentally from the planktonik cells of the same species [32].

An example for the cooperative existence is the interaction of the sulfate reducers and the sulfur oxidizers. Considering the main aggressive corrosion relevant microorganisms, the anaerobic sulfate reducers produce as a main metabolite the $\mathrm{H}_{2} \mathrm{~S} / \mathrm{S}^{2-}$ from sulfate ions. These molecules form an insoluble black precipitate with the $\mathrm{Fe}^{2+}$ ion. Then blackish deposit covers the surface that clearly indicates the formation of FeS and the activity of the anaerobe microorganisms. The protruding blackish deposits show the primer sulfate reducer colonies; beneath them the metal surface is more severely damaged, with other words here the metal dissolution is more visible due to the enhanced metabolic activity (Figure 5).

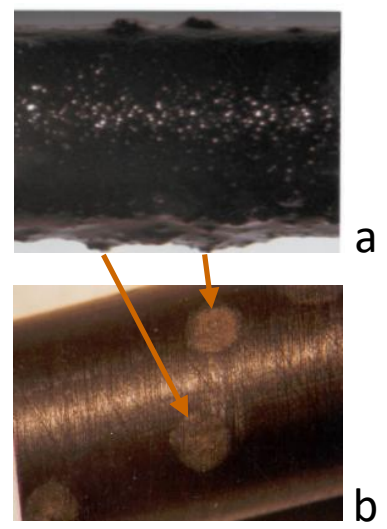

Figure 5. Mild steel surface after immersion into a broth inoculated with Desulfovibrio desulfuricans; a: the blackish biofilm with FeS that covers the metal surface; b: the metal surface after removal of the biofilm; the light spots represents the initial adsorption of the anaerobic microorganisms. 
In an important aerobic reaction the sulfide ions are transformed to sulfate ions via oxidation catalyzed by aerobic microorganisms. This shows that the corrosion relevant microorganisms are forming a so-called "autarchy" economy when the side products (metabolites) from one side of microbes are converted into the same component, which was originally altered to $\mathrm{H}_{2} \mathrm{~S}$. Biofilm formation involves the participation of different types of microorganisms thus their coherent coexistence is essential for their survival [33].

The biofilm not only protect the microorganisms from the external environment and let them live under safe condition but beneath the nanolayer starts the deterioration of metals when the first initiated pitting corrosion changes into general corrosion [34].

The bacterial corrosion is accompanied by formation of slimes and deposits of microbial, organic and inorganic origin and beneath them anaerobic conditions prevail.

The tendency of microorganisms to adhere to solid surfaces can be evaluated by different approaches like interaction energy, thermodynamics and by Derjaguin-LandauVerwey-Overbeek (DLVO) as well as extended DLVO theory. These are based on longand short-range forces between bacteria and the surface, by surface energy approach; the physical and chemical interactions between the solid surface and the biofilm should also take into consideration. Other parameters that may influence the rating process of bacterial accumulation on metals are the surface hydrophobicity or hydrophilicity as well as the surface roughness [35-42]. Surface wettability that influences fouler colonization ranges from superhydrophobic to superhydrophilic surfaces [43-45]. A hydrophobic surface exhibits low wettability and low surface energy, whereas a hydrophilic surface has high wettability and high surface energy.

The factors that play important role in the biofilm formation are the following:

1. Properties at the metal/solution interface: chemical composition, concentration of components in the aqueous environment, organic and inorganic ionic strength, $\mathrm{pH}$, surface oxide coverage (passive layer thickness), polarization, roughness; all these factors significantly influence the bacterial attachment, colonization and biofilm formation.

2. Bacteria/medium characteristics: the microbial cells - with some exceptions - are negatively charged at neutral $\mathrm{pH}$ values. The attachment of some corrosion relevant bacteria (Desulfovibrio desulfuricans, Desulfovibrio singaporenus, Pseudomonas) to iron alloy surfaces show the highest adhesion forces at $\mathrm{pH}$ values that are close to the isoelectronic points of bacteria.

Once microorganisms form a thick gelatinous layer, macroorganisms (e.g. mussels, alga, barnacles) present in natural waters can accumulate on the top of the biofilm and together with other inorganic insoluble chemicals (e.g. solid corrosion products) form a massive, well-adhered biodeposit that decreases the economic function/efficacy [42].

In order to carry out biocorrosion risk assessment, it is essential to have proper surface sampling, which should be followed by identification of microorganisms in the samples and by analysis of the water. 


\section{Classification of microorganisms}

The taxonomy is the science of classification of organisms, when new or existing microorganisms are identified. The organisms form two classes: prokaryotes and eukaryotes.

The prokaryotes have no nucleus and their multiplication goes by fission. The eukaryotes contain real nuclei and their division goes by mitosis. Fungi, algae and protozoa that take part in MIC are eukaryotic microorganisms; bacteria that are permanent participants in MIC are prokaryotes.

According to the morphology, physiology, and genetics the microorganisms can be categorized into three groups [46].

\subsection{Classification according to oxygen demand}

As to the oxygen demand bacteria can be classified into two groups: aerobic or anaerobic organisms.

Anaerobic microorganisms (or anaerobes) are those that do not require oxygen to their microbial activity. According to the oxygen demand the anaerobes are classified as:

- obligate anaerobes (the presence of oxygen is harmful);

- aerotolerant organisms: (they tolerate the presence of oxygen);

- facultative anaerobes (they can grow without oxygen but they use oxygen if it is present);

Aerobic microorganisms can live, grow and proliferate in oxygen environment. Their classification is the follow:

- obligate aerobes (they need oxygen in cellular respiration for oxidation of substrates like sugars, fats; in these reactions energy is generated);

- facultative aerobes (they use oxygen for energy production but they also use anaerobic method for energy production);

- microaerophiles (oxygen is required for energy production, but the atmospheric oxygen destroys them);

- aerotolerantes (they cannot use oxygen directly but the presence of oxygen does not destroy them).

\subsection{Classification of microorganisms according to the energy and carbon requirement}

Energy sources:

- Chemotrophs (respiration): they respire molecular oxygen as terminal electron acceptor (aerobic respiration); they also use nitrate (anaerobic respiration). Methane producers and many sulfate reducers belong to this group.

- Chemotrophs (fermentation): the energy derives from phosphorylation; 
- Chemolithoautotrophes: they obtain energy through oxidation of inorganic compounds and from $\mathrm{CO}_{2}$; sulfur and iron oxidizing bacteria, nitrifying bacteria belong to this group;

- Phototrophs: they gain energy by photophosphorylation; oxygen-evolving and not oxygen-evolving species belong to this group.

Carbon resource: this is the most important for all organisms.

- Heterotrophs: they supply the carbon need from organic compounds;

- Autotrophs: they utilize carbon dioxide;

- Chemoheterotrophs, chemoorganotrophs: generally the organotrophs use various organic compounds as carbon and energy source;

- Chemoautotrophs, chemolithotrophs: they are lithotrophs; the ATP is generated by oxidative phosphorylation;

- Myxotrophs: they are "chemolithotropic heterotrophs" using carbon dioxide;

- Photoheterotrophs and photoautotrophs: they utilize light as energy source and $\mathrm{CO}_{2}$ as carbon source.

\subsection{Classification of microorganisms according to taxonomic hierarchy}

Taxonomy classifies new and existing organisms. The hierarchy is the following: domainkingdom-phylum-class-order-family-genus-species-strains.

A simple summary about the microbial demand is demonstrated in the Table 1.

Table 1. The need of microorganisms for growth.

\begin{tabular}{|c|c|c|}
\hline requirements for microbes & supplied by & kind of growth \\
\hline energy source & light, chemical substances & phototrophic, chemotrophic \\
\hline carbon source & $\mathrm{CO}_{2}$, organic substances & autotrophic, heterotrophic \\
\hline $\begin{array}{l}\text { electron donor (which is } \\
\text { oxidized) }\end{array}$ & $\begin{array}{l}\text { inorganic substances, } \\
\text { organic substances }\end{array}$ & lithotrophic, organotrophic \\
\hline $\begin{array}{l}\text { electron acceptor (which is } \\
\text { reduced) }\end{array}$ & oxygen, $\mathrm{NO}_{2}^{-}, \mathrm{NO}_{3}^{-}, \mathrm{SO}_{4}^{2-}, \mathrm{CO}_{2}$ & aerobic, "anoxic" anaerobic \\
\hline
\end{tabular}

The most widely employed methods for classifying microbes are the follows:

1. morphological characteristics,

2. differential staining,

3. biochemical testing, DNA finger-print of DNA-base composition,

4. polymerase chain reaction, and DNA chips [47, 48].

After getting insight into the life of the microorganisms, in the next part those bacteria will be introduced that are mainly responsible for the biocorrosion. 


\section{Corrosion relevant microorganisms}

The role of microorganisms in the deterioration of materials can be classified into: biofouling, biodeterioration and biocorrosion (or MIC). There are about several dozens of microorganisms that cause MIC on iron, copper and aluminum alloys in humid or aqueous environment. Some microorganisms possess extreme tolerance to severe conditions such as acidic and alkaline environment, low and high pressure as well as wide temperatures and salt concentration range. Under very extreme conditions they are able to keep their activities (growing, metabolizing, and multiplying). They are able not only to tolerate such harsh conditions, but they can generate special conditions and create aggressive environments that promote directly or indirectly the metal deterioration.

\subsection{Microorganisms associated with MIC}

The most important chemolithotrophic corrosion relevant bacteria are the follows:

\subsubsection{Sulphate-reducing bacteria (SRB)}

This type of microorganisms has four subgroups: 1. proteobacteria; 2. firmicutes; 3. thermodesulfobacteria; 4. archea.

The anaerobe SRBs gain their energy by oxidizing organic compounds or molecular hydrogen $\left(\mathrm{H}_{2}\right)$ and reducing sulfate $\left(\mathrm{SO}_{4}^{2-}\right)$ ions to hydrogen sulfide $\left(\mathrm{H}_{2} \mathrm{~S}\right)$. With other words, they use sulfate ions instead of oxygen in the anaerobic respiration, and oxidize organic substances to organic acids or $\mathrm{CO}_{2}$ by the reduction of sulfate to sulfide. The sulfide metabolite can react with metal ions and produce metal sulfides (e.g. ferrous sulfide $(\mathrm{FeS}))$, that are poorly soluble in aqueous environment and make a dark sludge appearance (Figure 5).

The isolated SRBs might differ in their appearance or in the energy source they use. Some SRBs can use both elemental sulfur and sulfate as electron acceptors. Common SRB species include genera Desulfovibrionales, Desulfosporosinus, Desulfotomaculum, Syntrophobacterales, Desulfosporomusa, and Desulfobacterales. Thermodesulfovibrios are also found among them as a member of the Nitrospirae phylum. Two types of thermophilic sulfate-reducing bacteria exist that are active at higher temperature: thermodesulfobacteria and thermodesulfobium. In the biocorrosion where SRBs play important role, oxygen concentration cells are formed, $\mathrm{H}_{2} \mathrm{~S} / \mathrm{S}^{2-}$ are released that form insoluble precipitate, which leads to cathodical depolarization.

In order to understand how the SRBs can accelerate the corrosion, the equations below show the main reactions that take place in the presence of iron and SRB. The most important is the metal dissolution on the anode, and the reduction on the cathode. These anodic and cathodic reactions are summarized here:

anodic reaction:

water dissociation:
$4 \mathrm{Fe} \rightarrow 4 \mathrm{Fe}^{2+}+8 \mathrm{e}^{-}$

$8 \mathrm{H}_{2} \mathrm{O} \rightarrow 8 \mathrm{H}^{+}+8 \mathrm{OH}^{-}$ 
anodic depolarization:

dissociation of hydrogen sulfide:

anodic depolarization:

cathodic reaction:

hydrogen oxidation:

The overall reaction:

$$
\begin{aligned}
& 3 \mathrm{Fe}^{2+}+6 \mathrm{OH}^{-} \rightarrow 3 \mathrm{Fe}(\mathrm{OH})_{2} \\
& \mathrm{H}_{2} \mathrm{~S} \rightarrow \mathrm{S}^{2-}+2 \mathrm{H}^{+} \\
& \mathrm{Fe}^{2+}+\mathrm{S}^{2-} \rightarrow \mathrm{FeS} \\
& 8 \mathrm{H}^{+}+8 \mathrm{e}^{-} \rightarrow 4 \mathrm{H}_{2} \\
& \mathrm{SO}_{4}^{2-}+4 \mathrm{H}_{2} \rightarrow \mathrm{H}_{2} \mathrm{~S}+2 \mathrm{H}_{2} \mathrm{O}+2 \mathrm{OH}^{-} \\
& 4 \mathrm{Fe}+\mathrm{SO}_{4}^{2-}+4 \mathrm{H}_{2} \mathrm{O} \rightarrow \mathrm{FeS}+3 \mathrm{Fe}(\mathrm{OH})_{2}+2 \mathrm{OH}^{-}
\end{aligned}
$$

The formation of $\mathrm{FeS}$ and $\mathrm{Fe}(\mathrm{OH})_{2}$ solids shows clearly how the presence of microorganisms enhance the rate of corrosion.

\subsubsection{Iron and/or manganese oxidizing bacteria (IMB)}

These aerobic bacteria can metabolize by utilizing the oxidation of ferrous and/or manganese ions. The microbiologically produced ferric and/or manganese salt deposits are typically brown colored. The removal of a protective passive oxide films by these microorganisms leads to enhanced metal corrosion.

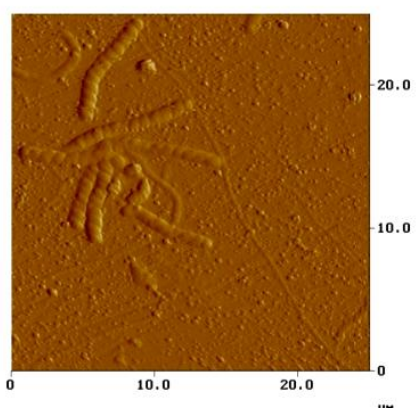

Figure 6. Iron oxidizing bacteria (Gallionella).

Iron-oxidizing bacteria, such as Gallionella (Figure 6), Sphaerotilus, Leptothrix and Crenothrix, which are often identified by their distinctive morphologies such as the extracellular twisted ribbon-like stalks formed by Gallionella ferruginea, oxidize the soluble ferrous iron $\left(\mathrm{Fe}^{2+}\right)$ to insoluble ferric iron $\left(\mathrm{Fe}^{3+}\right)$ (e.g. to $\left.\mathrm{Fe}(\mathrm{OH})_{3}\right)$. During the oxidation extremely aggressive ferric chloride ions are formed that alter the environment into very low local $\mathrm{pH} \cong 1$, which leads to formation of localized pits on iron alloy surfaces.

\subsubsection{Iron reducing bacteria (IRB)}

The IRBs are less important than the iron oxidizing bacteria though they also play role in the MIC. When IRBs are together with SRB, carbon steel metal samples will more severely damaged than in abiotic environment $[49,50]$. 
Several types of microorganisms (bacteria), including those from the genera Pseudomonas and Shewanella have the ability to reduce Mg and/or Fe oxides that also can influence the corrosion reactions.

\subsubsection{Pseudomonas aeruginosa}

This Gram-negative bacterium can be found almost everywhere in the environment; this also plays important role in initialization of MIC. They adhere to solids first (by their adhesion starts the biofilm formation), and then the other microorganisms use the pioneer colonies where to stack. The aerobic slime-former Pseudomonas can combine the thin gelatinous film with corrosion deposits formed on metal surfaces.
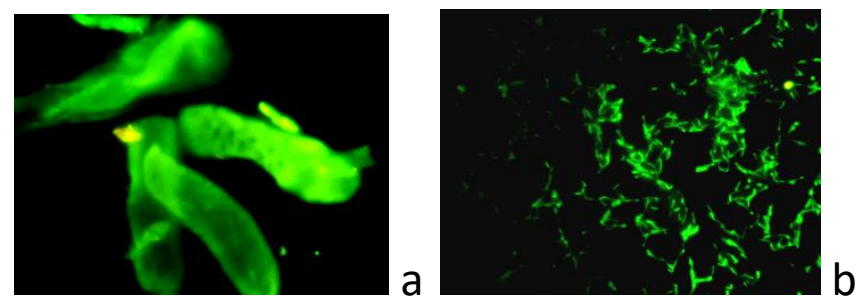

Figure 7. Pseudomonas aeruginosa a: single cells; b: scattered on a solid surface.

\subsubsection{Sulphur-oxidizing bacteria (SOB)}

Sulphur-oxidizing bacteria are aerobes that gain energy by oxidation of the reduced sulfur compound (e.g. $\mathrm{H}_{2} \mathrm{~S}$ ) into elemental sulfur $\left(\mathrm{S}^{0}\right)$ by partial oxidation, or to sulfate $\left(\mathrm{SO}_{4}^{2-}\right)$, which forms sulfuric acid $\left(\mathrm{H}_{2} \mathrm{SO}_{4}\right)$ in aqueous environment. Beggiatoa and Paracoccus are two classical examples of sulfur-oxidizing bacteria.

These aerobic sulfur-oxidizing prokaryotes belong to genera like Acidianus, Acidithiobacillus, Aquaspirillum Aquifex, Bacillus, Beggiatoa, Methylobacterium, Paracoccus, Starkeya, Sulfolobus, Thermithiobacillus, Thiobacillus, and Xanthobacter.

The most investigated genera of SOBs (Thiobacillus, Sulfolobus, Thermothrix, Beggiatoa, and Thiothrix) that biologically oxidize the sulfides are chemolithotrophs. Thiobacillus ferrooxidans, an acidophile, (active in the $\mathrm{pH}$ range of 1.0-2.5) and also thermophile, (prefer temperatures of $45-50^{\circ} \mathrm{C}$ ) oxidizes iron- and sulfur-containing minerals.

\subsubsection{Slime-former bacteria}

The slime formers (in the presence or absence of oxygen) produce a variety of extracellular mats of high-density slime that can cover partly or totally a solid surface. Their primary detrimental effects are due to the protection of anaerobes and aerobes, to the removal of metal ions by chelation, and to formation of pore plugging corrosion products. In formation of biofilm/biomass matures, aerobic bacteria consume oxygen, produce metabolic byproducts that are nutrient for anaerobes and these processes create real anaerobic environments underneath the biofilm. 


\subsubsection{Acid producer bacteria}

Acid producer bacteria form organic and inorganic acids as well as nutrients for other species, i.e. the generated fatty acids are used by other microorganisms (e.g. by SRBs). Recently, acid producing bacteria are recognized as a more dangerous microbial species connected with MIC due to their fermentative activities that alters the local $\mathrm{pH}$ within the biofilm, and it shifts it into more acidic range.

An example for the acid producing bacteria is the Thiobacillus thiooxidans that forms $\mathrm{H}_{2} \mathrm{SO}_{4}$, when corrosion proceeds and hydrogen is liberated in the cathodic reaction.

\section{Metals influenced by MIC}

Important topic is what the chemical composition of construction materials is as it determines the susceptibility of metals to abiotic (chemical) and biotic (microbiologically influenced) corrosion. The surface of the metallic substratum plays an essential role in the early stage of EPS and cell accumulation/distribution [51, 52].

It is difficult to predict in advance the place where the metal loss at high rate starts. It depends not only on the composition of the alloys but on the types and numbers of microbes as well as on the general conditions (temperature, nutrients for bacteria, $\mathrm{pH}$, salt content, etc.).

One should keep in mind that the metabolic products (e.g. sulfide, organic acids) alter the interface chemistry and result in increased corrosion rate because of the presence of EPS, $\mathrm{pH}$ - and dissolved oxygen gradients that lead first to localized (pitting and crevice), later to general corrosion, parallel with de-alloying [53-55].

On the other hand, a biofilm forms a diffusion barrier for certain chemical species (e.g. oxygen, nutrients, and aggressive ions like chloride) [56].

From economic point of view the MIC costs are very important; it is about $0.3-0.85$ GDP. The main industries affected by MIC are paper and pulp, waste treatment, chemical, petrochemical and power industries, to mention only some of them.

\subsection{Aluminum and aluminum alloys}

Aluminum often used in constructions especially in the aeronautic industry is a very useful metal owing to the resistance of $\mathrm{Al}_{2} \mathrm{O}_{3}$ passive film formed on the surface. But, unfortunately, it is very susceptible to localizes corrosion initialized by different ions (e.g. $\mathrm{Cl}^{-}$) and by microorganisms. At the metal surface the microbes accelerate the dissolution and alter the metal composition as well as the corrosion processes during the generation of biofilms. The mould Homoconis resinae is well-known in aircraft tanks as they use the fuel as carbon source. Not only the mycelium and the metabolites can deteriorate the aluminum alloys but the biomass formed on the surface can block the filters. 


\subsection{Iron and iron alloys}

Steels are often applied at industrial scale due to the passive films naturally or artificially formed on their surfaces. The stainless steels are different in grades, in basic composition, in finishing and in the surface treatment. All these effects influence the surface properties [57].

As to the alloying components, the following elements are important:

1. carbon: small quantity is necessary;

2. chromium: increases the hardeness, the toughness, at $10.5 \%$ the resistance to corrosion;

3. manganese: increases the hardeness, makes a steel more stable in the quench and less susceptible for cracking; neutralizes the negative effect of sulfur;

4. nickel: increases the strength, reduces the brittleness and the toughness;

5. molybdenum: increases the hardness, the tensile strength, increases the inhibition of uniform and localizes corrosion;

6. nitrogen, copper: significantly decrease the microbial adhesion [58].

Alloying elements that alter the chemical composition and thickness of passive film, stabilize the protective oxide layer, and alter the susceptibility to MIC.

Steel surfaces are generally resistant to corrosion because of their elemental composition, crystalline homogeneity and surface oxides. When undesired corrosion relevant microorganisms are present they can enhance the metal deterioration through destroying the passive oxide layer.

Very good publications summarize the role of alloying elements in MIC as well as the parameters that influence the microbial adhesion $[59,60]$.

There is a relationship between the microbial size/morphology/EPS production and the metal surface roughness [61]. The positively charged metal oxides surfaces enhance the microbial attachment as the microbe's surfaces are generally negatively charged.

The period of the microbial reproduction also affects the MIC. On carbon steel the microbial corrosion is accelerated in the exponential (log) growing phase and is stable during the stagnant and declining phase. Not only the bacterial number but the accumulated metabolic products influence the corrosion rate.

The MIC of carbon steel is mainly influenced by the formation of biogenic sulfides (which leads to the breakdown of the passive layer) that is followed by the cathodic depolarization (by hydrogenase enzymes).

The attack of corrosion relevant microorganisms on stainless steel 304 appears in localized corrosion. The presence of Pseudomonas bacteria changes the composition of the metal surface; the iron content decreases and the chromium content increases, which is followed parallel by appearance of micro-pits. The molybdenum at concentration $>6 \%$ (stainless steels 316L) decreases the possibility of MIC.

A good summary on the influence of the alloying elements $(\mathrm{Cr}, \mathrm{Ni}, \mathrm{Mo}, \mathrm{Ru})$ on the microbial adhesion and biofilm formation was published, and the microbiological attack 
and biofilm formation (visualized by light and atomic force microscopes) was correlated with the concentration of alloying elements [62]. Data clearly proved that not only the certain alloying content, but their ratio also influences the first microbial adhesion, the biofilm thickness and the chemical composition of the surface oxide layer, and, at the same time, the sensibility to microbial adhesion is also changed. The presence of Mo in the steel not only drastically enhances corrosion resistance but decreases/inhibits the microbiological adhesion. 3D atomic force microscopic images have proven the change in the oxide layer compactness caused by the presence of molybdenum, which can explain the special role of Mo in the MIC.

\subsection{Copper and copper alloys}

These metals are often used in cooling systems, in heat exchangers (chemical and nuclear power industry). The copper ions can control the microbial growth but corrosion relevant microorganisms can attack the metal and biofilm can grow on its surface [63].

\subsection{Titanium}

The titanium is a highly corrosion resistant metal. This is the reason that it could be used in highly corrosive environment, also in body fluid, but microorganisms can attach to its surface and form a biofilm [64].

\section{Techniques for monitoring and evaluating MIC [65]}

The collaboration of different experts is important to investigate the MIC. The microbiologically influenced corrosion should be studied by microbiological methods in order to identify the microbes that take part in the corrosive deterioration. The next step is the combination of the microbial tests with surface analytical methods as well as with electrochemical investigations. Techniques utilized for detection and monitoring of MIC include conventional electrochemical direct current (DC) methods, alternating current (AC) electrochemical impedance spectroscopy (EIS), optical and electron microscopy, atomic force microscopy (AFM), Fourier transform infrared spectrometry (FTIR), scanning vibrating electrode mapping (SVEM), concentric electrode technique, X-ray photoelectron spectroscopy (XPS) and Auger electron spectroscopy (AES) only mention some of them $[53,66,67]$.

Other important data on the main operating parameters in the MIC are the follows: flow rate, temperature, pressure, pigging frequency, chemical treatment history, and fluid physico-chemistry and chemical composition that all affect the MIC directly or indirectly.

\subsection{Electrochemical methods used to study the MIC}

There are several very good summaries on the advantages and disadvantages of electrochemical techniques used for study the MIC [68, 69]. 
Electrochemical methods applied in MIC research could be divided into main groups:

- no external signal is applied (e.g. measurement of redox potential $\left(E_{\mathrm{r}-\mathrm{o}}\right)$ or corrosion potential $\left(E_{\text {corr }}\right)$, as well as the electrochemical noise analysis (ENA));

- a small potential or current perturbation is applied (e.g., polarization resistance $\left(R_{\mathrm{p}}\right)$ and electrochemical impedance spectroscopy (EIS));

- the potential is scanned over a wide range (e.g., anodic and cathodic polarization curves, cyclic voltammetry).

The electrodes used in all electrochemical techniques measure the current and/or voltage to estimate the corrosion rate. The surface of the electrode alters in the course of the measurements because the formation of an electric double layer on the electrode surface. Additionally, in the presence of microorganisms, the vial cells build a biofilm; its thickness changes continuously. This is the reason for parallel application of several different electrochemical techniques in order to obtain more precise results on the surface reactions that help explain the mechanism of the MIC [67-70].

Different electrochemical techniques are shortly summarized below.

\subsection{Methods without external signal}

\subsubsection{Redox potential}

It measures the oxidizing power of the environment. The potential change of the prepassivated platinum electrode into the positive direction is the consequence of either the increase of the oxygen concentration or of the decrease in the $\mathrm{pH}$ value.

Microorganisms, by their presence or by their metabolic activity can drastically alter the local physico-chemical state at the interface of metal and the environment, which is responsible for the initiation and acceleration of localized corrosion [71, 72].

The advantage of this technique is that it could be used both in laboratory and in field tests. But this method does not give numerical information about the corrosion rate. Additionally, the immersion time (colonization on the electrode surface) influences the result.

\subsubsection{Corrosion potential ( $\left.E_{\text {corr }}\right)$}

The easiest electrochemical test is to monitor the corrosion potential but it gives the least information on the mechanism of the MIC as the reference electrode is not stable because of the continuous biofilm formation. It is not easy to interpret the $E_{\text {corr }}[72,73]$.

It simultaneously measures both the anodic and cathodic processes but only the trends could be assessed [55].

\subsubsection{Electrochemical Noise Analysis (ENA)}

By electrochemical noise analysis the potential and current fluctuations are measured simultaneously. No external signals are applied that could influence the biofilm formation 
and its properties. This technique gives the most accurate and realistic information on the corrosion caused by microorganisms but the interpretation of the curve is not easy [74].

\subsubsection{Micro-sensors}

Micro-sensors, microelectrodes are important tools in biofilm research because they inform about the local environments and measure the local interactions with high spatial resolution at microscale.

In the biofilm the presence and the metabolic activity of the microorganisms produce chemicals. Their concentration profiles provide useful information about the microbial activity and about the mass transport.

Most of micro-sensors used in biofilm research are amperometric micro-sensors that can measure the concentrations of dissolved gases, ions, and organic and inorganic molecules. The important characteristics of the micro-sensors are the tip diameters, sensor surfaces (for optimal spatial resolution), noise level, stability, selectivity [75].

Micro-sensors have been used to establish profiles of mixed species biofilms [76].

\subsubsection{Dual-cell technique}

At this technique a semi-permeable membrane separates two identical electrochemical cells. The dual cell allows the continuous monitoring of changes in corrosion caused by the presence of microbes and the biofilm [77]. Bacteria are present in one of the cells, and the sign and magnitude of the resulting galvanic current are monitored to show the bacterial activity. The dual-cell technique does not inform about the concrete corrosion rate, but monitor the changes in corrosion rate due to the presence of the biofilm.

\subsubsection{Capacitance}

This galvanostatic transient method can determine the capacitance. A constant-current pulse produces an overvoltage-time response. The applied current $\left(I_{\text {app }}\right)$ generates cathodic overvoltage $(\eta)$. After amplification through a high-impedance differential amplifier, signals are recorded by computer $[72,73]$.

\subsection{Methods applying small external signal}

\subsubsection{Electrochemical Impedance Spectroscopy (EIS)}

EIS technique records impedance data as a function of a signal frequency applied at a fixed electrode potential. Generally a large frequency range is investigated [78]. This technique provides information about the properties (compactness, porosity) on the layer formed on the electrode surface by analyzing the polarization resistance values, which informs about the influence of the microorganisms. 


\subsubsection{Polarization Resistance $\left(R_{p}\right)$ Method}

By measuring $R_{\mathrm{p}}$, the corrosion rate of any metal can be continuously monitored [79].

The exact calculation of $i_{\text {corr }}$ for a given time requires simultaneous measurements of $R_{\mathrm{p}}$ and anodic and cathodic Tafel slopes $\left(b_{\mathrm{a}}\right.$ and $\left.b_{\mathrm{c}}\right)$. Modern instruments are able to determine the precise values of $i_{\text {corr }}$. A simplification of the polarization resistance technique is the linear polarization technique [80].

Significant fluctuation of $R_{\mathrm{p}}$ with time are often observed for systems undergoing pitting or crevice corrosion because the $R_{\mathrm{p}}$ data are mainly applicable in case of general or uniform corrosion and less in localized corrosion, including MIC. The rapid and easy interpretation of these results is the advantage of the polarization resistance method. It shows good correlation with results got by gravimetrical method.

\subsection{Methods applying large signal polarization}

These techniques require potential scans ranging from several hundred millivolts to several volts. Potentiostatic or potentiodynamic polarization curves as well as pitting scans use large signal polarization [81]. Polarization curves can be used to determine corrosion currents $\left(i_{\text {corr }}\right)$ by Tafel extrapolation. Information can be obtained from experimental values of the anodic and cathodic Tafel slopes $\left(b_{\mathrm{a}}\right.$ and $\left.b_{\mathrm{c}}\right)$. Pitting scans are used to determine the pitting potential $\left(E_{\mathrm{pit}}\right)$ and the protection potential $\left(E_{\mathrm{prot}}\right)$.

Polarization curves could be used to determine the effects of microorganisms colonized on metal surfaces on the electrochemical processes [53].

The advantage of this technique is that it can be used under laboratory and field conditions and the interpretation of data is easy. But because of the large polarization signal, irreversible changes in surface properties could happen due to the application of large anodic or cathodic potentials (that can influence the microbial behavior, the growth and multiplication and the biofilm formation).

\section{Surface analytical methods}

\subsection{Microscopic techniques}

Microscopy (optical, electron, and scanning probe) has advantages and disadvantages though in the last decades the microscopic methods are improved concerning the microorganism's interaction with surfaces [83].

The visualization of microorganisms is not very easy because during multiplication they change their size and form, excrete chemicals. Their surface character is constantly changes, which is due to the EPS production. Three microscopic techniques are mainly applied in the MIC study. Confocal laser microscopy, scanning electron microscopy together with the environmental scanning electron microscopy and atomic force microscopy; all allow the visualization of microorganisms and observation of biofilm 
formation in real time. There are other microscopic techniques developed to visualization of MIC. [84].

\subsubsection{Scanning electron microscopy (SEM), environmental scanning electron microscopy (ESEM)}

SEM produces images of a sample by scanning it with a focused electron beam. A traditional SEM can produce images either by backscattered and/or by secondary electrons; and additionally, X-ray scattering can inform about the chemical composition of the solid surface [85].

Though SEM produces photographic information on a sample, but cannot quantitatively characterize the sample surface. SEM operates under high vacuum, which is a significant drawback in the study of MIC because of the dehydration of the microorganisms and the EPS around them.

The ESEM was developed by substantial alteration of SEM when only a part of the electrons scans the sample and that allows the measurement at less high vacuum (at higher pressure). This allows that the specimens are measured in their natural state by ESEM, which helps the visualization of biological samples in natural form. ESEM is useful tool to demonstrate the real structure of biofilms, cells embedded in the extracellular matrices on solid surfaces [86].

\subsubsection{Atomic force microscopy (AFM)}

Atomic force microscopy is based on the measurement of force between the scanning tip and the sample surface under investigation. From the MIC point of view, the 3D imaging (providing important information on the form, length, width, outer part of microbial cells) and the force measurements are mostly used. [88, 89].

In contrast to the SEM, the advantage of AFM is the higher resolution and, especially, that it does not require high vacuum. The measurement happens either in contact or noncontact mode, and, additionally, in tapping mode, which is very beneficial in case of soft, biological samples. AFM is able for topographical imaging of bacteria, biofilm, and corroded steel surfaces in high-resolution, and for quantification of localized corrosion by the so-called "section analysis" [90-94] (Figure 4,8).
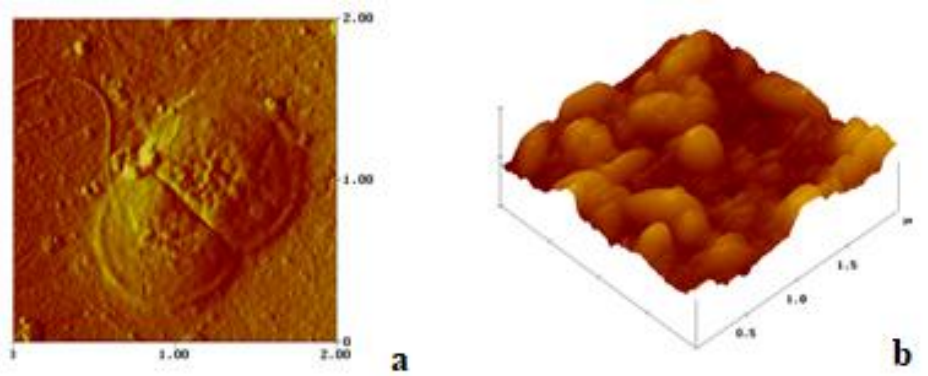

Figure 8. Microorganisms visualized by AFM; a: fission of an aerobe, its flagelum is well visible; b: Desulfovibrio desulfuricans cells on a solid surface $(\mathrm{z}=300 \mathrm{~nm})$. 


\subsubsection{Confocal Laser Microscopy (CLM)}

CLM is widely used in biological sciences. A laser light provides intense, coherent, collimated light necessary to penetrate into a thick specimen. The laser light excites fluorophores. Images of the $x-y$ plane (parallel to the surface) are collected automatically as a computer-controlled stepping motor alters the $z$ dimension (depth). The CLM provides 3D structures in micrometer range and shows the biofilm architecture in the native state: hydrated, living cells within the exopolymeric matrix [95].

\subsubsection{Confocal Laser Scanning Microscopy (CLSM)}

A laser beam, which passes the surface and excites fluorophores, is focused onto an area of the sample by an objective lens, and the emitted photons collected from the sample constitute images in 3D about the pre-selected depth level and time. The CLSM is suitable for in situ studying biofilms, and monitoring their formation. The importance of this method is that the microorganisms are visualized in their viable form; the distribution of the microbes within the biofilm is also monitored. Additionally, visualization of the interaction of bacteria (or other, corrosion relevant microorganisms) with the solid surface could help in understanding the MIC and it enables the kinetic study of MIC [96]

\subsubsection{Confocal Raman Microscopy (CRM)}

The spectral information of confocal microscopy can be absorption, reflection, transmission, emission, photoluminescence, fluorescence or Raman spectroscopy. In the 1990s micro-Raman spectroscopy was elaborated. The advantage of this microscope is the high collection efficiency of the Raman signal. This technique could extract the relevant chemical information from each spectrum and create a map on the distribution of the chemical components with a few micrometers lateral resolution [97].

In biological samples with microbial cells infrared spectra can inform on cellular components. The advantage of this technique is that it is applicable both in laboratory and under industrial conditions and it does not need any sample preparation. The usefulness of this method was proven by several research groups [98-100].

\subsection{Piezoelectric methods: Quartz crystal microbalance (QCM)}

QCM uses acoustic waves generated by oscillating a piezoelectric, single crystal quartz plate to measure mass variations. QCM is a sensitive gravimetric tool that can be used in biofilm and MIC related studies. The advantage of the QCM is the high sensitivity $\left(\mathrm{ng} \cdot \mathrm{cm}^{-2}\right)$, and continuous in situ data collection. This is a nondestructive monitoring technique, which could be combined with other methods like with voltammetry, EIS, optical spectroscopy, etc. QCM as a gravimetric tool can monitor the kinetics of bacterial mass accumulation during the biofilm formation [101-105].

The limitation of this technique is due to the viscoelastic nature of biofilms. This was the reason for developing a modified quartz crystal microbalance with dissipation mode 
(QCM-D). The time-dependent changes in the dissipation energy $(\Delta D)$ and crystal frequency $(\Delta f)$ predict the adhesion behavior of bacteria, which allows to follow the microbial interaction and the adhesion processes with the solid surface [106].

Though the QCM is an easy-to-use, low-cost device, it is not extensively applied in research laboratories for studying biofilms and MIC related microorganisms.

\subsection{Spectroscopic analytical methods}

Concerning the problems around the MIC, two methods are worthwhile to discuss: Fourier transform infrared spectroscopy and X-ray photoelectron spectroscopy.

\subsubsection{Fourier transform infrared spectroscopy (FTIR)}

The applicability of FTIR in biofilm study was recognized more than 20 years ago, when it was realized that by this technique the microorganisms could be identified in a noninvasive way as fingerprints of microorganisms.

The wavelength interesting in MIC study ranges between 2.5 and $20 \mu \mathrm{m}$ (in the medium infrared waves). The adsorption bands expressed in wavenumbers are proportional to the absorbed energy. In the spectrum the functional groups are represented in the range of 4000 and $1500 \mathrm{~cm}^{-1}$ and the deformation, bending and ring vibrations are below $1500 \mathrm{~cm}^{-1}$. This range could be the "fingerprint" of molecules.

In a flow cell the adhesion mechanisms between the biofilm and the solid surface was analyzed and it was proven that the binding process was initialized by the EPS. The microorganisms could be analyzed alone or embedded in EPS [107-109].

The disadvantage of the FTIR technique in the MIC analysis is that it cannot differentiate between living and dead cells, and the high water content of the biofilm disturbs the spectrum.

\subsubsection{X-Ray Photoelectron Spectroscopy (XPS)}

The samples are placed into ultra-high vacuum chamber, and are irradiated with X-ray that leads to formation of photoelectrons. These photoelectrons with their characteristic energies represent the atoms. The intensities of spectra are proportional to the concentration of atoms and indicate their oxidation states, i.e. the XPS spectrum gives information about the surface composition and about its chemical states $[110,111]$.

XPS can also inform about the microbial cell surface composition that represents mainly three molecular classes like polysaccharides, peptides and hydrocarbon-like compounds. XPS measurement on SRB anaerobic biofilms showed the oxygen depleted areas where sulfate reduction led to sulfide ion by SRB that caused thinning of the passive film and initiation of pitting attack [112]. In the research of MIC the disadvantage of the XPS technique is that it needs ultra-high vacuum where the hydrated samples will be dehydrated and it is not applicable under industrial conditions. 


\section{Mechanisms of the biocorrosion}

The mechanism of the MIC depends on the types of microbes associated with the corrosion, on their metabolites, on the composition of the EPS and on its exo-enzymes. It is important to emphasize that a multicultural microbial colonies cause much higher corrosion rate than a pure corrosion relevant microbial culture.

There are several descriptions of the MIC mechanisms. The most important reaction is the anodic metal dissolution; and the reduction on the cathode. To understand the metalmicrobe interaction, we have to take into account that under different conditions solid precipitates can form. The anaerobic microorganisms produce sulfide ions, which will result in the formation of insoluble iron sulfide. When oxygen is present, aerobic microbes produce solid metal oxides/hydroxides. According to the electron transfer hypothesis, electron transfer could take place through the EPS from the metal to the electron acceptor i.e. to the oxygen. Enzymes embedded in the biofilm as well as metal ions bound to bacterial EPS can also catalyze the cathodic reaction. For long time the hydrogenconsuming enzymes were considered to increase the corrosion rate. Now it is obvious that there are other enzymes (e.g. cellular catalyzes), that influence the MIC. In the classical theory the sulfate reducer bacteria increase the corrosion rate through the electron transport from the metal surface to the microbial sulfate reduction pathway. The important role of hydrogenase enzymes in the anaerobic MIC is reconfirmed.

King and Miller in 1971 [113] proposed other interesting mechanism. They emphasized that the solid iron sulfide is the absorber of the molecular hydrogen. The iron sulfide covered area constitutes the cathode, and the biofilm behaves as an anode. This leads to high galvanic corrosion rate with increased iron dissolution.

Romero in 2005 [114] worked out the mechanism of sulfate reducing bacteria in MIC of iron. According to his theory the first is the bacterial adsorption and iron sulfide production and then a micro-galvanic cell formation through the metallic surface and the iron sulfide. In the second stage the bacteria and the inorganics are in equilibrium. The third stage is controlled by the local $\mathrm{pH}$, the pyrite is reduced to mackinawite and severe localized corrosion starts. Galvanic corrosion is generated between the anodic metal and the cathodic iron sulfide with different compositions (without hydrogen permeation due to the barrier effect of the EPS). This is characteristic for the microorganisms in the exponentially growing period, which results in enough hydrogen sulfide ions. The most important steps are the biofilm formation and stabilization with hydrogen permeation, sulfidization and localized galvanic corrosion.

According to the recently described MIC mechanism on stainless steel in the presence of biofilm formed by sulfate reducer bacteria, iron oxidation happens on the outside of sessile cells while the utilization of the electrons released by the oxidation process for sulfate reduction occurs in the bacterial cell cytoplasm. In this case, cross-cell wall electron transfer is achieved by electrogenic biofilm. It is clear that the most important step in the MIC is the electron transfer. Both the riboflavin and flavin adenine dinucleotid, two 
common electron mediators enhance the electron transfer and accelerate the pitting corrosion (Figure 9)].

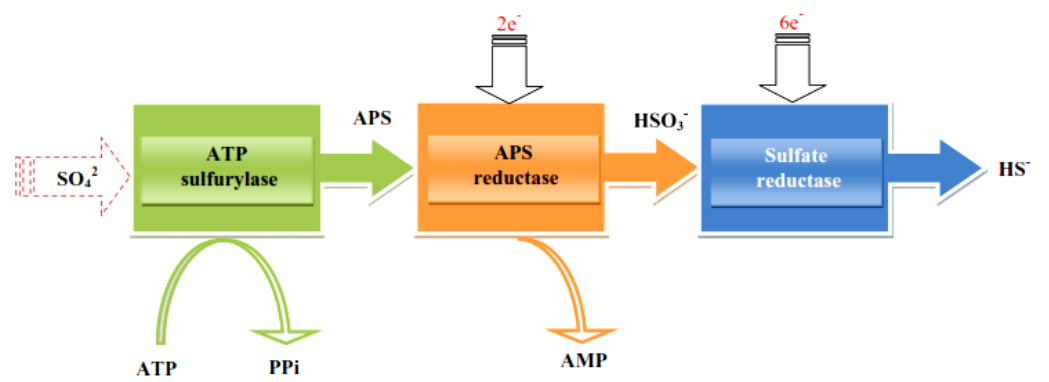

Figure 9. Microbial reductions of sulfate ions into sulfide [115].

In the latest review on the MIC mechanisms the concept of bioenergetics, electrontransfer theories and respiration types are discussed. When an environment lacks carbon source and other electron-donors that are necessary for the energy metabolisms, the microorganisms can utilize elemental iron or other energetic metals as electron-donors. This will lead to MIC. Two main types of anaerobic MIC on metals are classified according to the microbial respiration types. One is the extracellular electron transfer-MIC (EET-MIC) and the other one the metabolic MIC (M-MIC). These explanations show how MIC processes occur and how they are dependent on the environmental conditions. The characteristics of EET-MIC and M-MIC mechanisms provide useful insights into MIC by sulfate reducing, nitrate reducing and acid producing bacteria that are dominant in the anaerobic MIC processes [116, 117].

\section{Summary}

The paper has aimed to introduce a special type of corrosion, i.e. the microbiologically influenced corrosion and to explain that this is not a new type of metal corrosion but the microorganisms by their present, by the excreted metabolites with aggressive components (sulfide, organic and inorganic acids etc.) and with the glue-like exopolymeric substances enhance the chemical and electrochemical corrosion rate. The corrosion relevant microbes (both the anaerobes and the aerobes) were introduced and characterized, and their corrosion enhancing activity demonstrated. The formation of biofilms -built of microorganisms, of high water and inorganic and organic material content - was followed and the importance of the microorganisms built in the biomatrix was explained. Different measuring techniques were introduced that are useful in the research of the MIC, with emphasis on their advantages and disadvantages in study of MIC. The development in the explanation of MIC mechanisms, i.e. the history of the attack of corrosion relevant microbes, is also involved into the paper, which allows the demonstration how complex the microbial corrosion is. 


\section{References}

1. J.H. Garrett, The action of water on lead, 1891, H.K. Lewis, London.

2. R.H. Gaines, Bacterial Activity as a Corrosive Influence in the Soil, J. Ind. Eng. Chem. (Washington, D. C.), 1910, 2, 128-130. doi: 10.1021/ie50016a003

3. C.A.H. Von W. Kühr and L.S. van der Vlucht, Graphitization of cast iron as an electrobiochemical processes in anaerobics, Water, 1934, 18, no. 16, 147.

4. E. Miranda, M. Bethencourt, F.J. Botana, M.J. Canob, J.M. Sanchez-Amaya, A. Corzoc, J. Carciade Lomasc, M.L. Fardeaua and B. Olliviera, Biocorrosion of Carbon steel alloys by an Hydrogenotrophic Sulfat-Reducing Bacterium Desulfovibrio capillatus isolated from a Mexican Oil Field Separator, Corros. Sci., 2006, 48, $2417-$ 2431. doi: 10.1016/j.corsci.2005.09.005

5. E.S. Bastin, F.E. Greer, C.A. Merritt and G. Moulton, The presence of sulfate-reducing bacteria in oil field waters, Science, 1926, 63, 21-24. doi: 10.1126/science.63.1618.21

6. C.E. Zobell, The Effect of Solid Surfaces upon Bacterial Activity, J. Bacteriol., 1943, 46, 39-56.

7. H.A. Videla, Manual of Biocorrosion, 1996, CRC Press: Boca Raton, FL, pp 272.

8. B.J. Little and J.S. Lee, Microbiologically influenced corrosion: an update, Int. Mater. Rev., 2014, 59, no. 7, 384-393. doi: 10.1179/1743280414Y.0000000035.

9.W.G. Charaklis, M.J. Nimmons, B.F. Picolouglou, Biofilms and microbial fouling, $A d v$. Appl. Microbiol., 1983, 29, 93-138. doi: 10.1016/S0065-2164(08)70355-1

10. W.G. Charaklis, M.J. Nimmons and B.F. Picolouglou, Influence of fouling biofilms on heat transfer, Heat Transfer Eng., 1981, 3, 23-37. Published online: 27 Mar. 2007. doi: 10.1080/01457638108939572

11. B.E. Christensen and W.G. Charaklis, Biofilms, 1990, J. Wiley, N.Y., 796.

12. A.M. Rouhi, The Squeeze On Tributyltins, Chem. Eng. News, 1998, 76, 41-42. doi: 10.1021/cen-v076n017.p041

13. J.V. Costerton, K.-J. Cheng, J.C. Nickel, M. Dasgupta, T.J. Marie, G.G. Geesey and T.I. Ladd, Bacterial biofilms in nature and disease, Annu. Rev. Microbiol., 1987, 41, 435-434. doi: 10.1146/annurev.mi.41.100187.002251

14. H.-C. Flemming, T. Griebe and G. Schaule, Antifouling strategies in technical systems - A short review, Water Sci. Technol., 1996, 34, 517-524. doi: 10.1016/02731223(96)00687-7

15. A.W. Decho, Microbial exopolymer secretions in ocean environments: their role(s) in food webs and marine processes, Biol. Annuel. Rev., 1990, 28, 73-153.

16. P.A. Wilderer and W.G. Charaklis, Chemistry of Aquatic Systems: Local and Global Perspectives, Dahlem Workshop, 1988, J. Wiley \& Sons, 5-17.

17. H.G. Hoppe, in: Microbial Adhesion and Aggregation, Springer Verlag, Berlin, Ed.: K.C. Marshall, 1984, 283-301. 
18. J.-H. Chen, L.W. Lion, W.C. Ghiorse and M.L. Shuler, Mobilization of adsorbed cadmium and lead in aquifer material by bacterial extracellular polymers, Water Res., 1995, 29, 421-430. doi: 10.1016/0043-1354(94)00184-9

19. A. Jahn and P.H. Nielsen, Cell biomass and exopolymer composition in sewer biofilm, Wat. Sci. Technol., 1998, 37, 17-24. doi: 10.1016/S0273-1223(97)00751-8

20. S. Comte, Interactions intre des exopolymeres extraits de biomasses epuratioires et les metaux, THESE N ${ }^{\circ}$ 2005-53, Docteure de l'Universite de Limoges, 2005.

21. R.M. Donlan, Biofilms: Microbial Life on Surfaces, Emerging Infect. Dis., 2002, 8, no. 9, 881-890. doi: 10.3201/eid0809.020063

22. P.G. Rouxhet and N. Mozes, Physical chemistry of the interaction between attached microorganisms and their support, Water Sci. Technol., 1990, 22, 1-16. doi: 10.2166/wst.1990.0131

23. J.H. Pringle and M. Fletcher, Influence of substratum wettability on attachment of freshwater bacteria to solid surfaces, Appl. Environ. Microbiol., 1983, 45, 811-817.

24. D.J. Uhliger and D.C. White, Relationship between physiological status and formation, Appl. Environm. Microbiol., 1988, 45, 64-67.

25. B. Frølund, T. Giebe and P.H. Nielsen, Enzymatic activity in the activated-sludge floc matrix. Appl. Microbiol. Biotechnol., 1995, 43, 755-761.

26. W.G. Charaklis, "Microbial Fouling Control" in: Biofouling, Eds.: W.G. Charaklis and K.C. Marshall, J. Wiley, N.Y, 1990.

27. Microbial Biofilms: Current Research and Applications, Eds: G. Lear and G.D. Lewis, Caister Academic Press, New Zealand, 2012, ISBN: 978-1-904455-96-7.

28. H.C. Flemming, J. Wingender, R. Moritz, W. Borchard and C. Mayer, Physio-chemical properties of biofilms: a short review, Biofilms in the aquatic environment, Eds.: C.W. Keevil, A. Godfree, D. Holt and C. Dow, Cambridge, UK: The Royal Society of Chemistry, 1999, 1-12.

29. P. Stoodley, K. Sauer, D.G. Davies and J.W. Costerton, Biofilms as complex differentiated communities, Annu. Rev. Microbiol., 2002, 56, 187-209.

30. A.I. Railkin, Marine biofouling colonization processes and defenses, Boca Raton, FL: CRC Press, 2004.

31. J.W. Costerton, G.G. Geesey and K.J. Chang, How bacteria stick, Sci. Am., 1978, 238, 86-96. doi: $10.1038 /$ scientificamerican0178-86

32. J.W. Costerton, Z. Lewandowski, D.E. Caldwell, D.R. Corber and H.M. Lappin-Scott, Microbial biofilm, Annu. Rev. Microbiol., 1995, 49, 711-745.

33. S.W. Borenstein, Microbiologically Influenced Corrosion. Handbook, in: Woodhead Publishing Series in Metals and Surface Engineering, Woodhead Publishing, Cambridge, UK, 2004. doi: 10.1533/9781845698621.frontmatter

34. J. Telegdi, A. Shaban, L. Trif, Chapter 8: Microbiology-Influenced Corrosion (MIC). in: Trends in Oil and Gas Corrosion Research and Technologies, 1st Edition, Production and Transmission, Ed.: A.M. El-Sherik, Elsevier, Woodhead Publishing, 2017, 191-214, ISBN: 978-0-08-101105-8. 
35. J. Telegdi, Microbiologically Influenced Corrosion; Chapter 6, Ed.: K. Demadis, In: Water Treatment Processes, Nova Science Publisher, 2012, 145-167.

36. J. Telegdi, T. Szabó, F. Al-Taher, É. Pfeifer, E. Kuzmann and A. Vértes, Coatings against corrosion and microbial adhesion, Mater. Corros., 2010, 61, no. 12, 10011007. doi: $10.1002 /$ maco.201005797

37. J. Telegdi, L. Románszki, F. Al-Taher, É. Pfeifer and E. Kálmán, Nanolayers against microbial adhesion, NACE Int. Corros., 2009, p. no. 3987.

38. G. Diósi, J. Telegdi, Gy. Farkas, L.G. Gazsó and E. Bokori, Corrosion influenced by biofilms during wet nuclear waste storage, Int. Biodeterior. Biodegrad., 2003, 51, no. 2, 151-156. doi: 10.1016/S0964-8305(02)00138-5

39. P. Gumpel, N. Arlt, J. Telegdi, D. Schiller and O. Moose, Microbiological influence on the electrochemical potential of stainless steel, Mater. Corros., 2006, 57, 715-723. doi: 10.1002/maco.200503962

40. J. Telegdi, A. Shaban, J. Beczner, Zs. Keresztes and E. Kálmán, Biofilm formation controlled by quartz crystal nanobalance, Mater. Sci. Forum, 1998, 289-292, 77-82. doi: 10.4028/www.scientific.net/MSF.289-292.77

41. B. El Gammudi, I. El Musrati, A. Bourgheya and A. El Tawil, Microscopic study of bacterial attachment on AISI 304 and AISI 316 stainless steel, Int. J. Integr. Biol., 2008, 42, 72-77.

42. J. Telegdi, L. Trif, L. Románszki, Chapter 9: Smart anti-biofouling composite coatings for naval applications, in: Smart composite coatings and membranes: Transport, structural, environmental and energy applications, Ed.: M.F. Montemor, Woodhead Publishing, 2016, 123-155. ISBN:978-1-78242-283-9

43. C. Hellio and D. Yebra, Advances in marine antifouling coatings and technologies, Boca Raton, FL: CRC Press, 2009.

44. Y.C. Jung and B. Bhushan, Wetting behavior of water and oil droplets in three-phase interfaces for hydrophobicity/philicity and oleophobicity/philicity, Langmuir, 2009, 25, 14165-14173. doi: 10.1021/la901906h

45. J. Genzer and K. Efimenko, Recent developments in superhydrophobic surfaces and their relevance to marine fouling: a review, Biofouling, 2006, 22, 339-360. doi: $\underline{10.1080 / 08927010600980223}$

46. ASM International, Corrosion in the Petrochemical Industry, Second ed., Ed.: V. Burt, Essential Research, ASM International, 2015, 426.

47. G. Keramas, D.D. Bang, M. Lund, M. Madsen, H. Bunkenborg, P. Telleman and C.B.V. Christensen, Use of Culture, PCR Analysis, and DNA Microarrays for Detection of Campylobacter jejuni and Campylobacter coli from Chicken Feces, J. Clin. Microbiol., 2004, 42, no. 9, 3985-3991. doi: 10.1128/JCM.42.9.3985-3991.2004

48. R. Eckert and T.L. Skovhus, Using Molecular Microbiological Methods to Investigate MIC in the Oil and Gas Industry, Materials Performance, 2011, 50, no. 8, 50-54. 
49. I.B. Beech, Corrosion of technical materials in the presence of biofilms - Current understanding and state-of-the art methods of study, Int. Biodeterior. Biodegrad., 2004, 53, no. 3, 177-183. doi: 10.1016/S0964-8305(03)00092-1.

50. H. Mansouri and S.A. Alavi, A study of microbial influenced corrosion in oil and gas industry, Conference Paper, (Teheran) The $1^{\text {st }}$ International Conference of Oil, Gas, Petrochemicals and Power Plants, 2012, 15-27. doi: 10.13140/RG.2.1.3117.8089

51. W. Teugleus, N.V. van Assche, I. Sliepen and M. Quirynen, Effect of material characteristics and/or surface topography on biofilm development, Clin. Oral Implants Res., 2006, 17, 68-81. doi: 10.1111/j.1600-0501.2006.01353.x

52. D. Clover, B. Kinsella, B. Pejcic and R. DeMarco, The influence of microstructure on the corrosion rate of various carbon steels, J. Appl. Electrochem., 2005, 35, 139-149. doi: $10.1007 / \mathrm{s} 10800-004-6207-7$

53. J.B. Little and J.S. Lee, Microbiologically Influenced Corrosion, Wiley, Hoboken, NJ, 2007.

54. R. Bhola, S.M. Bhola, B. Mishra and D.L. Olson, Microbiologically Influenced Corrosion and Its Mitigation: A review, Mater. Sci. Res. India, 2010, 7, no. 2, 407412. doi: $10.13005 / \mathrm{msri} / 070210$

55. R. Javaherdashtri, Microbiologically Influenced corrosion: An Engineering Insight, Springer, London, 2008.

56. B. Little, P. Wagner and F. Mansfeld, Microbiologically influenced corrosion of metals and alloys, Int. Mater. Rev., 1991, 36, 253-272. doi: 10.1179/imr.1991.36.1.253.

57. C-O.A. Olsson and D. Landol, Passive films on stainless steels-chemistry, structure and growth, Electrochim. Acta, 2003, 48, 1093-1104. doi: 10.1016/S0013-4686(02)008411

58. K.C. Hwanga, S. Lee and H.Ch. Leeb, Effects of alloying elements on microstructure and fracture properties of cast high speed steel rolls: Part I: Microstructural analysis, Mater. Sci. Eng.: A, 1998, 254, no. 1-2, 282-295. doi: 10.1016/S09215093(98)00626-1.

59. H.A. Videla, Biocorrosion and biofouling of metals and alloys of industrial usage; Present state of the art at the beginning of the new millennium, Rev. Metal. (Madrid, Spain), 2003, 256-264. doi: 10.3989/revmetalm.2003.v39.iExtra.1128

60. M. Hocevar, M. Jenko, M. Godec and D. Drobne, An overview of the influence of the stainless steel surface properties on bacterial adhesion, Mater. Tehnol., 2014, 48, no. 5, 609-617.

61. C. Díaz, M.C. Cortizo, P.L. Schilardi, et al., Influence of the Nano-micro structure of the surface on bacterial adhesion. Mater. Res., 2007, 10, no. 1. doi: 10.1590/S151614392007000100004

62. J. Telegdi, Influence of alloying elements on adhesion of corrosion relevant bacteria, Corrosion Protection (Ochrona przed Korozja), 2018, 61, 15-19. doi: $\underline{10.15199 / 40.2018 .6 .2}$ 
63. J.R. Ibars, J.L. Polo, D.A. Moreno, C. Ranninger and J.M. Bastidas, An impedance study on admiralty brass dezincification originated by Microbiologically Influenced Corrosion, Biotechnol. Bioeng., 2004, 87, 856-862. doi: 10.1002/bit.20197

64. D.A. Moreno, E. Cano, J.R. Ibars, J.L. Polo, F. Montero and J.M. Bastidas, Initial stages of microbiologically influenced tarnishing on titanium after 20 months of immersion in freshwater, Appl. Microbiol. Biotechnol., 2004, 64, 593-598. doi: 10.1007/s00253-003-1472-7

65. L. Trif, A. Shaban and J. Telegdi, Electrochemical and surface analytical techniques applied to microbiologically influenced corrosion investigation, Corros. Rev., 2018, 36, no. 4, 1-15. doi: 10.1515/corrrev-2017-0032

66. B.L. Little, P. Wagner and F. Mansfeld, An overview of microbiologically influenced corrosion, Electrochim. Acta, 1992, 37, 2185-2194. doi: 10.1016/00134686(92)85110-7

67. B.L. Little, F. Mansfeld, P.J. Arps and J.C. Earthman, Microbiologically influenced Corrosion, In: Encyclopedia of Electrochemistry, Wiley-VCH Verlag GmbH \& Co., 2007. doi: 10.1002/9783527610426.bard040603

68. S.C. Dexter, O.W. Siebert, D.J. Duquette and H. Videla, Use and limitation of electrochemical techniques for investigating microbiological corrosion, Corrosion, 1989, paper no. 616. doi: $10.5006 / 1.3585258$

69. W. Wang, J. Wang, H. Xu and X.B. Li, Electrochemical techniques used in MIC studies, Mater. Corros., 2006, 57, no. 10, 800-804. doi: 10.1002/maco.200503966

70. B.J. Little, P.A. Wagner, Application of Electrochemical Techniques to the Study of Microbiologically Influenced Corrosion, in: J.O. Bockris, B.E. Conway and R.E. White (eds.), Modern Aspects of Electrochemistry. Modern Aspects of Electrochemistry, 2002, 34, 205-246, Springer, Boston, MA. doi: 10.1007/0-306-46923-5_5

71. X. Zhang, R.A. Buchanan, E.E. Stansbury and N.J.E. Dowling, Electrochemical responses of structural materials to microbially influenced corrosion, CORROSION'89, NACE International, Houston, 1989, TX. No.512.

72. B.L. Little and P.A. Wagner, Application of electrochemical techniques to the study of MIC, In: Modern Aspects of Electrochemistry, New York: Kluwer Academic, Plenum Publishers, 2001.

73. W.H. Dickinson, F. Caccavo and Z. Lewandowski, The ennoblement of stainless steel by manganic oxide biofouling, Corros Sci., 1996, 38, 1407-1422. doi: $10.1016 / 0010-$ 938X(96)00031-5

74. U. Bertocci, C. Gabrielli, F. Huet and M. Keddam, Noise resistance applied to corrosion measurements. I. Theoretical analysis, J. Electrochem. Soc., 1997, 144, 3137. doi: $10.1149 / 1.1837361$

75. W. Lee and D. de Beer, Oxygen and $\mathrm{pH}$ microprofiles above corroding mild steel covered with a biofilm, Biofouling, 1995, 8, 273-280. doi: $\underline{10.1080 / 08927019509378280}$ 
76. Z. Lewandowski, MIC and biofilm heterogeneity, CORROSION/2000, NACE International, Houston, TX, 2000, No. 400.

77. R.B. Miller, A. Sadek, A. Rodriguez, M. Iannuzzi, C. Giai, J. Senko and C.N. Monty, Use of an Electrochemical Split Cell Technique to Evaluate the Influence of Shewanella oneidensis Activities on Corrosion of Carbon Steel, Ed.: A. Al-Ahmad, PLoS ONE, 2016, 11, 1 e0147899. doi: 10.1371/journal.pone.0147899.

78. P.L. Beese, H. Venzlaff, J. Srinivasan, J. Garrelfs, M. Stratmann and K.J. Mayrhofer, Monitoring of anaerobic microbially influenced corrosion via electrochemical frequency modulation, Electrochim. Acta, 2013, 105, 239-247. doi: 10.1016/j.electacta.2013.04.144

79. F. Mansfeld, The polarization resistance technique for measuring corrosion currents, in Advances in Corrosion Science and Technology, Eds.: M.G. Fontana and R.W. Staehle, New York, Plenum Press, 1976, 6, 163-262.

80. F. Mansfeld and B. Little, A technical review of electrochemical techniques applied to microbiologically influenced corrosion, Corros. Sci., 1991, 32, no. 3, 247-272. doi: 10.1016/0010-938X(91)90072-W

81. G. Schmitt, Sophisticated electrochemical methods for MIC investigation and monitoring, Mater. Corros., 1997, 48, 586-601. doi: 10.1002/maco.19970480905

82. Uhlig's Corrosion Handbook, Third ed., Ed.: R.W. Revie, John Wiley \& Sons INC, 2011.

83. A. Steele, D. Goddard and I. Beech, The use of atomic force microscopy in study of the biodeterioration of stainless steel in the presence of bacterial biofilms, Int. Biodeterior. Biodegrad., 1990, 34, 35-46. doi: 10.1016/0964-8305(94)90018-3

84. Y.F. Dufrêne, Application of atomic force microscopy to microbial surfaces: from reconstituted cell surface layers to living cells, Micron, 2001, 32, 153-165. doi: 10.1016/S0968-4328(99)00106-7

85. R.S. Khandpur, Handbook of Analytical Instruments, Third ed., McGraw Hill Education (India) Private Limited, 2015.

86. A.B. Ronner and A.C.L. Wong, Biofilm development and sanitizer inactivation of Listeria monocytogenes and Salmonella typhimurium on stainless steel and buna-n rubber, J. Food Prot., 1993, 56, 750-758. doi: 10.4315/0362-028X-56.9.750

87. J.W. Arnold and G.W. Bailey, Surface finishes on stainless steel reduce bacterial attachment and early biofilm formation: scanning electron and atomic force microscopy study, Poult. Sci., 2000, 79, 839-845. doi: $10.1093 /$ ps/79.12.1839

88. S.A. James, L.C. Powell and C.J. Wright, Atomic Force Microscopy of BiofilmsImaging, Interactions, and Mechanics, (chapter 6), In: Microbial Biofilms - Importance and Applications, Ed.: D. Dhanasekaran, InTech, 2016. doi: 10.5772/63312

89. G. Binning, C. Quate and Ch. Gerber, Atomic force microscope, Phys. Rev. Lett., 1986, 56, 930-933. doi: 10.1103/PhysRevLett.56.930 
90. L.Ch. Xua, K-Y. Chanb and H.H.P. Fanga, Application of atomic force microscopy in the study of microbiologically influenced corrosion, Mater. Charact., 2002, 48, 195-203. doi: 10.1016/S1044-5803(02)00239-5

91. L.C. Xu, H.H.P. Fang and K.Y. Chan, Atomic force microscopy study of microbiologically influenced corrosion of mild steel, J. Electrochem. Soc., 1999, 146, 4455-4460. doi: 10.1149/1.1392658

92. S. Stroes-Gascoyne and J.M. West, An overview of microbial research related to highlevel nuclear waste disposal with emphasis on the Canadian concept for the disposal of nuclear fuel waste, Can. J. Microbiol., 1996, 42, no. 4, 349-366. doi: 10.1139/m96051

93. J. Telegdi, J. Beczner, Zs. Keresztes, F.H. Kármán and E. Kálmán, Inhibition of microbiologically induced corrosion, In: Microbioal degradation processes in radioactive waste repository and in nuclear fuel storage areas, Eds.: J.H. Wolfram, R.D. Rogers and L.G. Gazso, Kluwer Academic Publisher NATO ASI Series, 1. Disarmament Technologies, 1997, 178-186.

94. J. Telegdi, Zs. Keresztes, G. Pálinkás, E. Kálmán and W. Sand, Microbially influenced corrosion as revealed by atomic force microscopy, Appl. Phys. A, 1998, 66, S639S642. doi: $10.1007 / \mathrm{s} 003390051215$

95. M. Kuehn, M. Hausner, H-J. Bungartz, M. Wagner, P.A. Wilderer and S. Wuertz, Automated confocal laser scanning microscopy and semi-automated image processing for analysis of biofilms, Appl. Environ. Microbiol., 1998, 64, 4115-4127. doi: 10.1128/AEM.64.11.4115-4127.1998

96. H. Li, E. Zhou, D. Zhang, D. Xu, J. Xia, C. Yang, H. Feng, Z. Jiang, X. Li, T. Gu and K. Yang, Microbiologically Influenced Corrosion of 2707 Hyper-Duplex Stainless Steel by Marine Pseudomonas aeruginosa Biofilm, Sci. Rep., 2006, 6, 20190. doi: 10.1038/srep20190.

97. Confocal Raman Microscopy, Eds.: T. Dieing, O. Hollricher and J. Toporski, SpringerVerlag Berlin Heidelberg, 2010. ISBN 978-3-642-12521-8.

98. C. Sandt, T. Smith-Palmer, J. Pink, L. Brennan and D. Pink, Confocal Raman microspectroscopy as a tool for studying the chemical heterogeneities of biofilms in situ, J. Appl. Microbiol., 2007, 103, 1808-1820. doi: 10.1111/j.13652672.2007.03413.x

99. B.D. Beier, R.G. Quivey, Jr. and A.J. Berger, Identification of different bacterial species in biofilms using confocal Raman microscopy, J. Biomed. Opt., 2010, 15, 066001-1-066001-5. doi: 10.1117/1.3505010

100. B.D. Beier, R.G. Quivey and A.J. Berger, Raman microspectroscopy for species identification and mapping within bacterial biofilms, AMB Express, 2012, 2, 35. doi 10.1186/2191-0855-2-35

101. D.E. Nivens, J.Q. Chambers, T.R. Anderson and D.C. White, Long-term, on-line monitoring of microbial biofilms using a quartz crystal microbalance, Anal. Chem., 1993, 65, 65-69. doi: 10.1021/ac00049a013 
102. J.J.T. Babauta, C.A. Beasley and H. Beyenal, Investigation of electron transfer by Geobacter sulfurreducens biofilms by using an electrochemical quartz crystal microbalance, ChemElectroChem, 2014, 1, 2007-2016. doi: 10.1002/celc.201402127

103. J. Wegener, A. Janshoff and C. Steinem, The quartz crystal microbalance as a novel means to study cell-substrate interactions in situ, Cell Biochem. Biophys., 2001, 34, 121-151. doi: 10.1385/CBB:34:1:121

104. A-C. Olofsson, M. Hermansson and H. Elwing, Use of a quartz crystal microbalance to investigate the antiadhesive potential of N-acetyl-l-cysteine, Appl. Environ. Microbiol., 2005, 71, 2705-2712. doi: 10.1128/AEM.71.5.2705-2712.2005

105. V. Reipa, J. Almeida and K.D. Cole, Long-term monitoring of biofilm growth and disinfection using a quartz crystal microbalance and reflectance measurements, $J$. Microbiol. Methods, 2006, 66, 449-459. doi: 10.1016/j.mimet.2006.01.016

106. M.C. Dixon, Quartz crystal microbalance with dissipation monitoring: enabling realtime characterization of biological materials and their interactions, J. Biomol. Tech., 2008, 19, 151-158.

107. A. Tunlid, D.E. Nivens, H. Jansson and D.C. White, Infrared monitoring of adhesion of Catenaria anguillulae zoospores to solid surfaces, Exp. Mycology, 1991, 15, 206-214. doi: $10.1016 / 0147-5975(91) 90022-6$

108. D. Helm, H. Labischinski, G. Schallehn and D. Naumann, Classification and identification of bacteria by Fourier-transform infrared spectroscopy, J. Gen. Microbiol., 1991, 137, 69-79. doi: 10.1099/00221287-137-1-69

109. P.D. Nichols, J.M. Henson, J.B. Gugkert, D.E. Nivens and D.C. White, Fourier transform infrared spectroscopic methods for microbial ecology: analysis of bacteria, bacteria-polymer mixtures and biofilms, J. Microbiol. Methods, 1985, 4, 79-94. doi: 10.1016/0167-7012(85)90023-5

110. S. Hofmann, Depth profiling, In: Practical Surface Analysis by Auger and X-ray Photoelectron Spectroscopy, Eds.: D. Briggs and M.P. Seah, John Wiley \& Sons Inc., New York, 1983, 141-179.

111. D. Briggs and J.C. Riviere, Spectral interpretation, In: Practical Surface Analysis by Auger and X-ray Photoelectron Spectroscopy, Eds.: D. Briggs and M.P. Seah, John Wiley \& Sons Inc., New York, 1983, 87-139.

112. G. Chen, R.J. Palmer and D.C. White, Instrumental analysis of microbiologically influenced corrosion, Biodegradation, 1997, 8, 189-200. doi: 10.1023/A:1008229419434

113. R.A. King and J.D.A. Miller, Corrosion by the Sulphate-reducing Bacteria, Nature, 1971, 233, no. 5320, 491-492. doi: $10.1038 / 233491 \mathrm{a} 0$

114. M. de Romero, Z. Duque, L. Rodríguez, O. de Rincón, O. Pérez and I. Araujo, A Study of Microbiologically Induced Corrosion by Sulfate-Reducing Bacteria on Carbon Steel Using Hydrogen Permeation, CORROSION, 2005, 61, 68-75. doi: 10.5006/1.3278162 
115. J. Telegdi, A. Shaban and Gy. Vastag, Surface Science and Electrochemistry of Interfacial Chemistry, in: Encyclopedia of Interfacial Chemistry: Biocorrosion-steel, Ed.: P. Vadgama, 2017.

116. B. Little, J. Lee and R. Ray, Microbiologically Influenced Corrosion: Global Phenomena, Local Mechanisms, Conference Proceeding, 20110224061 REPORT DATE: 17-02-2011. Naval Research Laboratory Stennis Space Center, MS, USA 39525.

117. Y. Li, D. Xu, Ch. Chen, X. Li,X., R. Jia, D. Zhang, W. Sand, F. Wang and T. Gu, Anaerobic microbiologically influenced corrosion mechanisms interpreted using bioenergetics and bioelectrochemistry: A review. J. Mater. Sci. Technol., 2018, 34, 1713-1717. doi: $10.1016 /$ j.jmst.2018.02.023 